Article

\title{
Graphene Oxide Concentration Effect on the Optoelectronic Properties of ZnO/GO Nanocomposites
}

\author{
Issam Boukhoubza ${ }^{1,2}$, Mohammed Khenfouch ${ }^{2}$, Mohamed Achehboune ${ }^{1,2}$, Liviu Leontie ${ }^{3}$, \\ Aurelian Catalin Galca ${ }^{4}{ }^{(}$, Monica Enculescu ${ }^{4, *}$, Aurelian Carlescu ${ }^{5}$, \\ Mohammed Guerboub ${ }^{1}{ }^{1}$, Bakang Moses Mothudi ${ }^{6}$, Anouar Jorio ${ }^{1}$ and Izeddine Zorkani ${ }^{1}$ \\ 1 Group of Nanomaterials and Renewable Energies, Laboratory of Solid State Physics, Faculty of Sciences \\ Dhar el Mahraz, Sidi Mohammed Ben Abdellah University, P.O. Box 1796, Atlas Fez 30 000, Morocco; \\ boukhoubza.issam00@gmail.com (I.B.); achehboune.mohamed01@gmail.com (M.A.); \\ mohammedguerboub@gmail.com (M.G.); a_jorio@hotmail.com (A.J.); izorkani@hotmail.com (I.Z.) \\ 2 Africa Graphene Center, Department of Physics, College of Science, Engineering and Technology, \\ Science Campus, University of South Africa, Cnr Christiaan de Wet \& Pioneer Avenue, \\ Florida 1709, Johannesburg, South Africa; khenfouch@yahoo.fr \\ 3 Faculty of Physics, Alexandru Ioan Cuza University of Iasi, Bulevardul Carol I, nr. 11, 700506 Iasi, Romania; \\ lleontie@gmail.com \\ 4 Laboratory of Multifunctional Materials and Structures, National Institute of Materials Physics, \\ Atomistilor 405A, 077125 Magurele, Romania; ac_galca@infim.ro \\ 5 Integrated Center for Studies in Environmental Science for North-East Region, Alexandru Ioan Cuza \\ University of Iasi, Bulevardul Carol I, nr. 11, 700506 Iasi, Romania; aurelian.carlescu@uaic.ro \\ 6 Department of Physics, University of South Africa, Private Bag X90, Florida 1710, South Africa; \\ mothubm@unisa.ac.za \\ * Correspondence: mdatcu@infim.ro
}

Received: 15 July 2020; Accepted: 31 July 2020; Published: 5 August 2020

check for updates

\begin{abstract}
In this work, the effects of graphene oxide (GO) concentrations (1.5 wt.\%, $2.5 \mathrm{wt.} \%$, and $5 \mathrm{wt.} \%$ ) on the structural, morphological, optical, and luminescence properties of zinc oxide nanorods ( $\mathrm{ZnO} \mathrm{NRs}$ )/GO nanocomposites, synthesized by a facile hydrothermal process, were investigated. X-ray diffraction (XRD) patterns of NRs revealed the hexagonal wurtzite structure for all composites with an average coherence length of about 40-60 nm. A scanning electron microscopy (SEM) study confirmed the presence of transparent and wrinkled, dense GO nanosheets among flower-like $\mathrm{ZnO}$ nanorods, depending on the GO amounts used in preparation. Raman spectroscopy, Fourier transform infrared spectroscopy (FTIR), ultraviolet-visible (UV-Vis) absorption spectroscopy, and photoluminescence (PL) measurements revealed the impact of GO concentration on the optical and luminescence properties of $\mathrm{ZnO} \mathrm{NRs} / \mathrm{GO}$ nanocomposites. The energy band gap of the $\mathrm{ZnO}$ nanorods was independent of GO concentration. Photoluminescence spectra of nanocomposites showed a significant decrease in the intensities in the visible light range and red shifted suggesting a charge transfer process. The nanocomposites' chromaticity coordinates for CIE 1931 color space were estimated to be $(0.33,0.34)$, close to pure white ones. The obtained results highlight the possibility of using these nanocomposites to achieve good performance and suitability for optoelectronic applications.
\end{abstract}

Keywords: ZnO NRs/GO nanocomposites; hydrothermal method; CIE diagram; optoelectronic properties 


\section{Introduction}

Recent developments in material science and nanostructures have required the synthesis of new versatile materials. With a wide direct band gap $(\sim 3.3 \mathrm{eV})$ and high exciton binding energy $(\sim 60 \mathrm{meV})$ at room temperature, a low cost, and an easy synthesis of different related nanostructures, zinc oxide $(\mathrm{ZnO})$ has emerged as one of the most attractive metal oxides widely used for optoelectronic applications [1,2]. Among $\mathrm{ZnO}$-based nanostructures, the nanorod (NR)-like shape has attracted great attention, due to their properties as well as the low reaction temperature, economic advantages, and facile synthesis [3]. Furthermore, one-dimensional $\mathrm{ZnO}$ nanostructures display unique electron transport properties that make them suitable for integration into devices, such as field-effect transistors [4]. The synthesis of nanocomposites based on $\mathrm{ZnO}$ and graphene or graphene oxide (GO) appears to be one of the most promising and cost-effective approaches, to control the morphology, band gap, and surface defect states of $\mathrm{ZnO}$ nanostructures [5]. Graphene derivative-based structures are key building blocks for many novel technological applications, such as photocatalysts [6], biosensors [7], batteries [8], or supercapacitors [9]. In particular, graphene oxide (GO) has gained attention as a material platform in modern material technology due to its mechanical, electric, thermal, and optical properties that can be readily tailored by a simple chemical functionalization [10,11]. Otherwise, GO is known for its high solubility due to the different functional groups including hydroxyl and epoxide on its surface and also for the inexpensive techniques of production [12], which have facilitated its use in device fabrication [13].

In recent years, many works have been reported about the combination of $\mathrm{ZnO}$ nanorods (NRs) with graphene oxide for developing various photonic and optoelectronic applications. Vessali et al. [14] improved $\mathrm{ZnO}$ NR/GO layers through a chemical bath deposition (CBD) method, for volatile organic compound detection. Chung et al. [15] developed polysulfone (PSF)-nanohybrid (membranes using a $\mathrm{ZnO}-\mathrm{GO}$ composite in order to obtain enhanced performance with an improved permeability rate. Rokhsat et al. [16] improved the photocatalytic activity of GO/ZnO nanorod films by UV irradiation. Alamdari et al. [17] presented a cost-effective method for the preparation of a GO-ZnO nanocomposite for a UV detection application. Qi el al. [18] studied the performance of ZnO/GO hybrids as an anode for lithium ion batteries. Khorramshahi et al. [19] reported the synthesis of a Mg-doped ZnO:GO nanocomposite and its properties for acetic acid-sensing applications.

In this study, we prepared $\mathrm{ZnO} \mathrm{NRs} / \mathrm{GO}$ nanocomposites with different $\mathrm{GO}$ amounts by a simple hydrothermal process. Different techniques, including X-ray diffraction (XRD), scanning electron microscopy (SEM), as well as Raman, Fourier transform infrared (FTIR), ultraviolet-visible-near-infrared (UV-Vis-NIR), and photoluminescence (PL) spectroscopies, were used to study the effects of GO concentration on surface defects and on the structural, surface morphological, optical, and luminescence properties of $\mathrm{ZnO}$ NRs/GO nanocomposites. Our findings contribute to understanding the optical properties of nanocomposites, which is important for the development of promising UV-Vis optoelectronic devices, based on graphene derivatives.

\section{Materials and Methods}

\subsection{Synthesis of $\mathrm{ZnO} N R / G O$ Nanocomposites}

$\mathrm{ZnO}$ nanorods/GO nanocomposites were obtained using a simple hydrothermal process. The chemicals used in this study were purchased from Sigma-Aldrich Chemie GmbH, Taufkirchen, Germany. First, GO was synthesized using the Hummers method [20]. Second, an equimolar aqueous solution of $0.1 \mathrm{M}\left(\mathrm{Zn}\left(\mathrm{NO}_{3}\right)_{2} \cdot 6 \mathrm{H}_{2} \mathrm{O}\right)$ and $0.1 \mathrm{M}$ hexamethylenetetramine was dissolved in deionized water. Then, this solution was transferred into a Teflon-lined stainless steel autoclave and heated at $120{ }^{\circ} \mathrm{C}$ for $24 \mathrm{~h}$. The $\mathrm{ZnO}$ nanorods/GO nanocomposites were synthesized by the same procedure as pure $\mathrm{ZnO}$. The GO solutions with $1.5 \mathrm{wt} . \%, 2.5 \mathrm{wt} \%$, and $5 \mathrm{wt} \%$ concentrations were added to this mixture. Finally, the solutions were transferred into a Teflon-lined stainless steel autoclave. Then, the autoclave was kept at $90{ }^{\circ} \mathrm{C}$ for $6 \mathrm{~h}$. The as-obtained products were filtered and washed 
several time using deionized water, and then were casted on glass substrates, and dried at $90^{\circ} \mathrm{C}$ for $2 \mathrm{~h}$ in air. The synthesis process is presented in Figure 1.

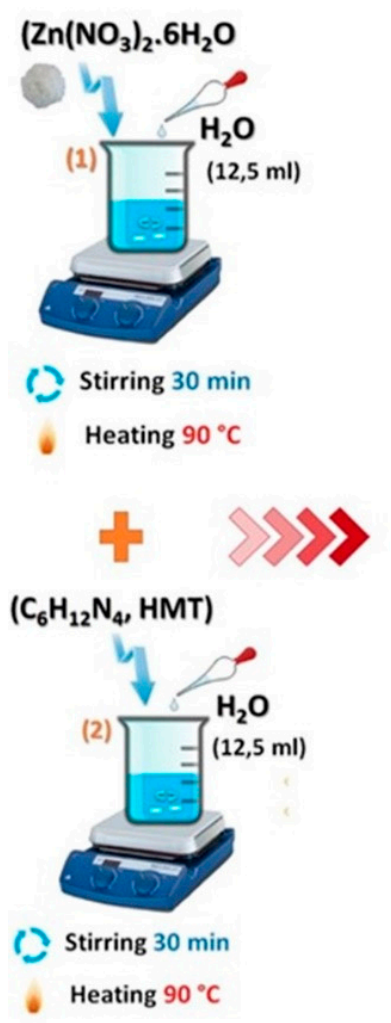

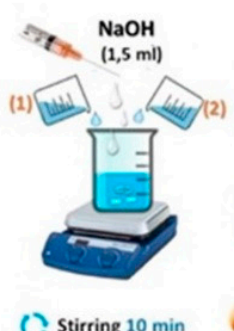

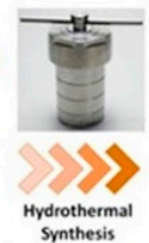

Stirring $10 \mathrm{~min}$

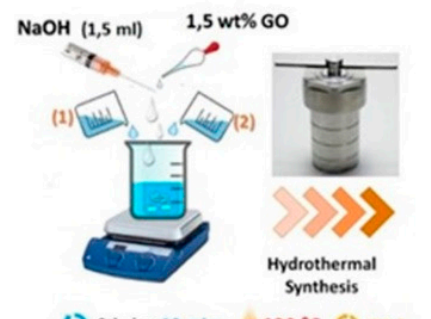

( Stirring $10 \mathrm{~min} \quad 120^{\circ} \mathrm{C} \bigcirc 24 \mathrm{~h}$
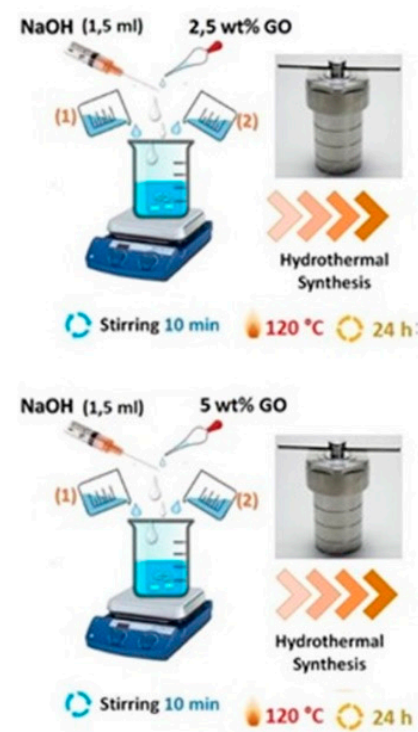

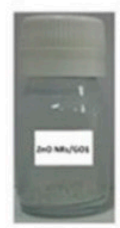

Drop Casting
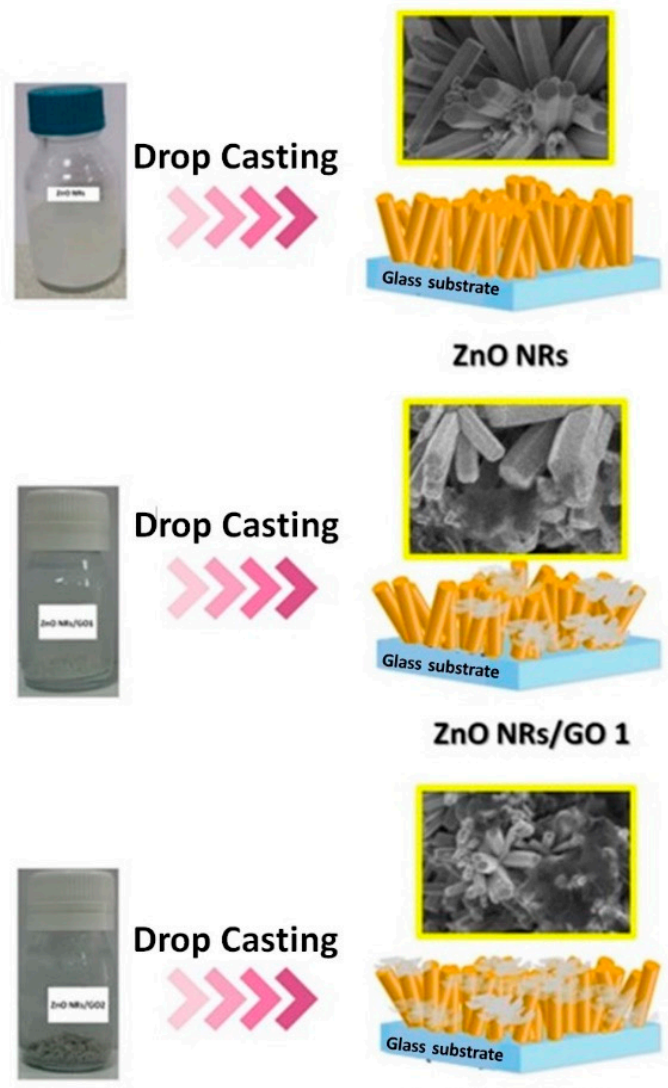

ZnONRs

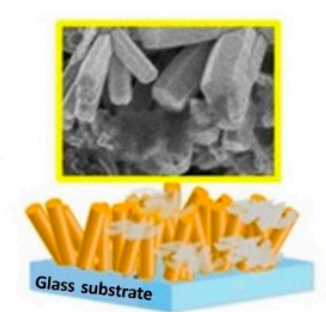

ZnONRs/GO 1
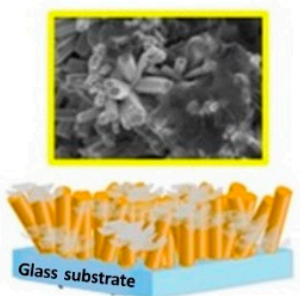

ZnONRs/GO 2

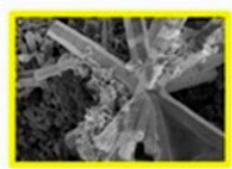

Drop Casting

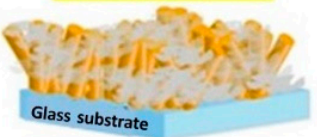

ZnONRs/GO 3

Figure 1. Preparation process of zinc oxide nanorods ( $\mathrm{ZnO}$ NRs)/graphene oxide (GO) nanocomposites.

\subsection{Characterization}

The crystal structure of the composites was determined with an X-ray diffractometer (Rigaku Smart Lab system) using CuK $\alpha$ radiation $(\lambda=1.54178 \AA$ ). A field-emission scanning electron microscope (FESEM) JEOL Model JSM 6390F, (JEOL USA, Inc., Peabody, MA, USA) working in high and low vacuum from 0.5 to $30 \mathrm{kV}$ accelerating voltage, equipped with an LaB6 cathode, InLens, and SE2 detectors, and an energy-dispersive X-ray spectrometer (EDX) (Bruker Nano GmbH, Berlin, Germany) were used to characterize the surface morphology of the samples. Raman and FTIR spectroscopic studies were performed in order to analyze the chemical composition in the nanocomposites employing a BRUKER-RFS27 FT-Raman spectrometer (Bruker Optik GmbH, Bremen, Germany) and a PerkinElmer FTIR spectrometer (PerkinElmer, Inc., MA, USA) respectively. A PerkinElmer LAMBDA 45 UV/Vis/NIR spectrometer (PerkinElmer, Inc., MA, USA) was used for measuring the specular transmission. The steady state PL measurements were done using $325 \mathrm{~nm}$ UV excitation at room temperature using 
an Edinburgh FL 920 photoluminescence spectrometer (Livingston, UK) with double monochromators and a $450 \mathrm{~W}$ Xe lamp as the excitation source.

\section{Results and Discussion}

\subsection{XRD Analysis}

The XRD analysis was carried out to investigate the crystal structure and phase composition of the $\mathrm{ZnO}$ nanorods and $\mathrm{ZnO} \mathrm{NRs} / \mathrm{GO}$ nanocomposites with different concentrations of $\mathrm{GO}$ (Figure 2). Both $\mathrm{ZnO}$ nanorods and $\mathrm{GO} / \mathrm{ZnO}$ nanorods exhibit diffraction peaks at $2 \theta=31.8^{\circ}, 34.5^{\circ}, 36.5^{\circ}, 47.8^{\circ}$, $56.6^{\circ}, 62.8^{\circ}, 66.5^{\circ}, 67.9^{\circ}, 69.3^{\circ}$, and $76.9^{\circ}$, assigned to the (100), (002), (101), (102), (110), (103), (200), (112), (201), and (202) crystalline planes, respectively, of hexagonal wurtzite ZnO (JCPDS-ICDD card no. 36-1451), $\mathrm{P} 6_{3} \mathrm{mc}$ space group [21,22]. The average crystallite size of $\mathrm{ZnO}$ NRs was calculated using the Debye-Scherrer equation of the (101), (002), (101) diffraction planes. The average size of $\mathrm{ZnO}$ nanorods within nanocomposites is slightly smaller for increasing GO concentration in comparison with that of $\mathrm{ZnO}$ NRs; this might be due to the cleavage of some bigger nanorods during the hydrothermal process [23]. Furthermore, the intensity of the peaks corresponding to $\mathrm{ZnO}$ NRs decreased from $\mathrm{ZnO}$ NRs to ZnO NRs/GO nanocomposites, which is obviously visible from the XRD pattern and may be due to the functionalization of $\mathrm{GO}$ by $\mathrm{ZnO}$ nanorods and the decreases in the crystallite size of $\mathrm{ZnO}$.

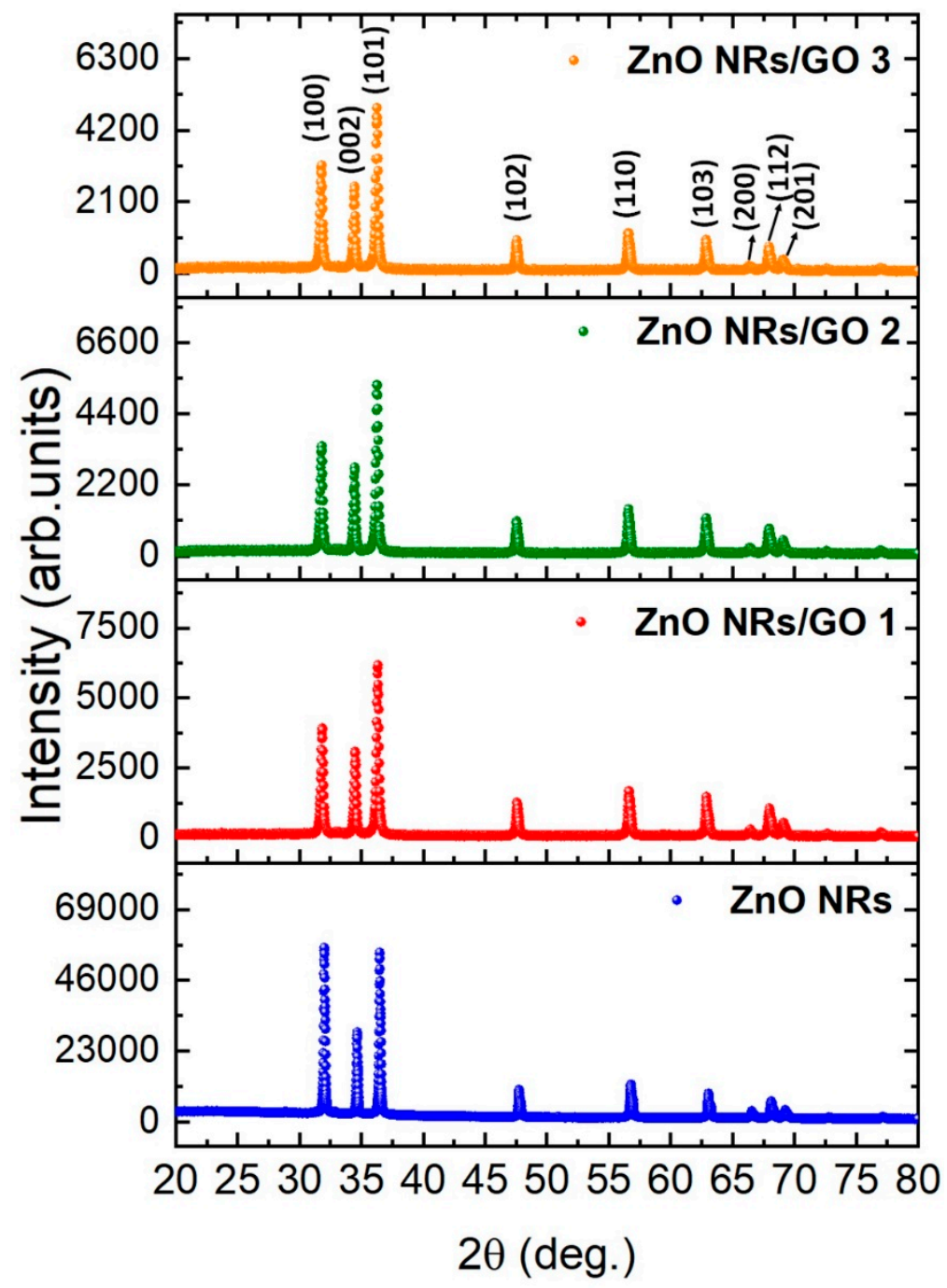

Figure 2. X-ray diffraction (XRD) patterns of ZnO NRs and ZnO NRs/GO nanocomposites with different concentrations of GO. 
The variation of lattice parameters of $\mathrm{ZnO}$ NRs with different GO concentrations can be calculated by means of a hexagonal lattice relation [24] as follows:

$$
\frac{1}{d^{2}}=\frac{4}{3}\left(\frac{h^{2}+h k+k^{2}}{a^{2}}\right)+\frac{l^{2}}{c^{2}}
$$

where $d$ is the interplanar distance and $h, k$, and $l$ denote Miller indices; a and c refer to the lattice constants of the hexagonal structure. The average crystallite size (D), or more precisely the coherent lengths along a crystallographic direction, of $\mathrm{ZnO}$ NRs can be calculated using the Debye-Scherrer equation [25] as follows:

$$
D=\frac{K \lambda}{\beta \cos (\theta)}
$$

where $k$ is a dimensionless shape factor, $\lambda$ is the $X$-ray wavelength, $\beta$ is the line broadening at half height of the maximum intensity (FWHM), and $\theta$ is the Bragg angle. The d-spacing values for $\mathrm{ZnO}$ nanoparticles were calculated using Bragg's law (Equation (3)):

$$
n \lambda=2 \mathrm{~d} \sin (\theta)
$$

where $n$ is a positive integer (equal to 1$), \lambda$ is the wavelength of the incident $X$-ray beam $(\lambda=1.54178 \AA$ ), and $\theta$ is the angular position of the hkl reflection. The values of lattice constants and crystallite sizes were determined accordingly and are summarized in Table 1.

\begin{tabular}{|c|c|c|c|c|c|c|c|}
\hline & & SEM & & & & XRD & \\
\hline Samples & $\begin{array}{c}\text { Diameter } \\
(\mathbf{n m})\end{array}$ & $\begin{array}{l}\text { Length } \\
(\mathrm{nm})\end{array}$ & Shape & $\begin{array}{l}\text { Crystallite } \\
\text { Size (nm) }\end{array}$ & d-Spacing ( & $\begin{array}{c}\text { Lattice } \\
\mathrm{A}=\mathrm{b}(\AA)\end{array}$ & $\begin{array}{c}\text { Parameter } \\
\text { c ( } \mathrm{A})\end{array}$ \\
\hline ZnO NRs & $\sim 175 \pm 3$ & $\sim 922 \pm 2$ & $\begin{array}{l}\text { Nanorods/ } \\
\text { nanoflowers }\end{array}$ & $\begin{array}{l}100-51.34 \\
002-60.32 \\
101-45.46\end{array}$ & $\begin{array}{l}2.817 \\
2.604 \\
2.478\end{array}$ & 3.25 & 5.20 \\
\hline $\begin{array}{c}\mathrm{ZnO} \\
\mathrm{NRs} / \mathrm{GO} 1\end{array}$ & $\sim 120 \pm 2$ & $\sim 882 \pm 2$ & $\begin{array}{l}\text { Nanorods/ } \\
\text { nanoflowers }\end{array}$ & $\begin{array}{l}100-44.93 \\
002-60.32 \\
101-45.47\end{array}$ & $\begin{array}{l}2.815 \\
2.603 \\
2.476\end{array}$ & 3.25 & 5.20 \\
\hline $\begin{array}{c}\mathrm{ZnO} \\
\mathrm{NRs} / \mathrm{GO} 2\end{array}$ & $\sim 104 \pm 8$ & $\sim 699 \pm 2$ & $\begin{array}{l}\text { Nanorods/ } \\
\text { nanoflowers }\end{array}$ & $\begin{array}{l}100-39.94 \\
002-45.24 \\
101-40.42\end{array}$ & $\begin{array}{l}2.814 \\
2.601 \\
2.476\end{array}$ & 3.25 & 5.20 \\
\hline $\begin{array}{c}\mathrm{ZnO} \\
\text { NRs/GO3 }\end{array}$ & $\sim 146 \pm 7$ & $\sim 773 \pm 2$ & $\begin{array}{l}\text { Nanorods/ } \\
\text { nanoflowers }\end{array}$ & $\begin{array}{l}100-44.93 \\
002-40.22 \\
101-40.42\end{array}$ & $\begin{array}{l}2.809 \\
2.598 \\
2.472\end{array}$ & 3.24 & 5.20 \\
\hline
\end{tabular}

Table 1. Values of average diameter, length, with the standard deviations of the distributions, crystallite size, d-spacing, and lattice parameters of $\mathrm{ZnO}$ NRs and $\mathrm{ZnO}$ NRs/GO nanocomposites.

This 101 interplanar spacing was found to slightly decrease, because of a smaller number of oxygen-containing groups produced by the one-pot hydrothermal treatment during ZnO NRs/GO growth [26,27].

\subsection{SEM and EDX Studies}

Figure 3a-d shows high-resolution SEM images of $\mathrm{ZnO}$ NRs and $\mathrm{ZnO}$ NRs/GO nanocomposites evaluated using JSM 6390 FESEM, working at an applied voltage of $1.8 \mathrm{kV}$ and a working distance of $5 \mathrm{~mm}$. In the absence of GO (Figure 3a), as-obtained $\mathrm{ZnO}$ nanorods display a flower-shaped hexagonal section morphology, indicating a high degree of crystallinity. Figure $3 \mathrm{~b}-\mathrm{d}$ shows the presence of 
several GO nanosheets among flower-shaped ZnO nanostructures. Obviously, GO layers are roughly transparent and, as their amount increases, the layers get thicker because of their tendency to be aggregated by van der Waals forces [28] (Figure 3d). It should also be noted that SEM micrographs show similar morphological features for different $\mathrm{ZnO}$ amounts in nanocomposites, depending on the initial GO concentration. By increasing the GO concentration from GO1 = $1.5 \mathrm{wt}$. $\%$ to GO3 = $5 \mathrm{wt}$. $\%$, the density of the $\mathrm{ZnO}$ nanorods decreased. In addition, SEM images of nanocomposites revealed few-layered graphene oxide sheets, no folds with a flat surface, which indicates a high quality of GO. These results indicate the formation of $\mathrm{ZnO} / \mathrm{GO}$ nanocomposites.
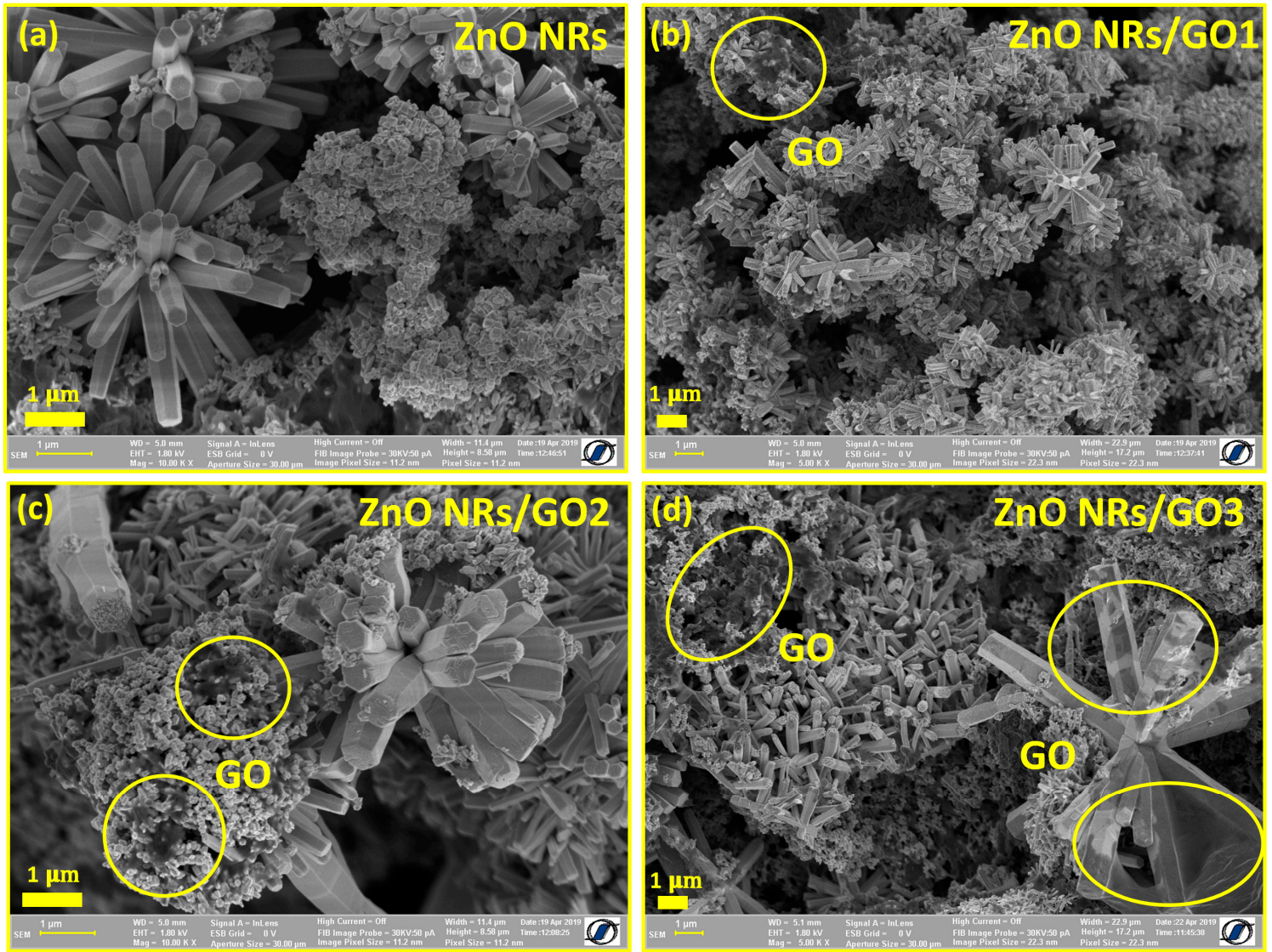

Figure 3. Field-emission scanning electron microscope (FESEM) images of (a) ZnO NRs, (b) ZnO NRs/GO1, (c) ZnO NRs/GO2, and (d) ZnO NRs/GO3 nanocomposites.

Figure 4 shows the histograms fitted by Gaussian distribution. As can be inferred from this figure, $\mathrm{ZnO}$ nanorods display an average diameter of $\sim 175 \mathrm{~nm}$ and an average length of $\sim 922 \mathrm{~nm}$ (Figure 4a,b). Moreover, the average size in diameter and length of $\mathrm{ZnO}$ nanorods in all nanocomposites (Figure 4c-h) is lower compared to those of pure ZnO NRs. Table 1 summarizes the size information for all samples based on SEM characterization and XRD measurements.

The atomic composition of ZnO NRs (Figure 5) is confirmed by EDX analysis. For ZnO NRs/GO nanocomposites, the presence of $\mathrm{Zn}, \mathrm{O}$, and $\mathrm{C}$ atoms is revealed. The EDX results are in good agreement with the expected chemical composition, which clearly indicates that $\mathrm{ZnO} / \mathrm{GO}$ nanocomposites were successfully synthesized. 

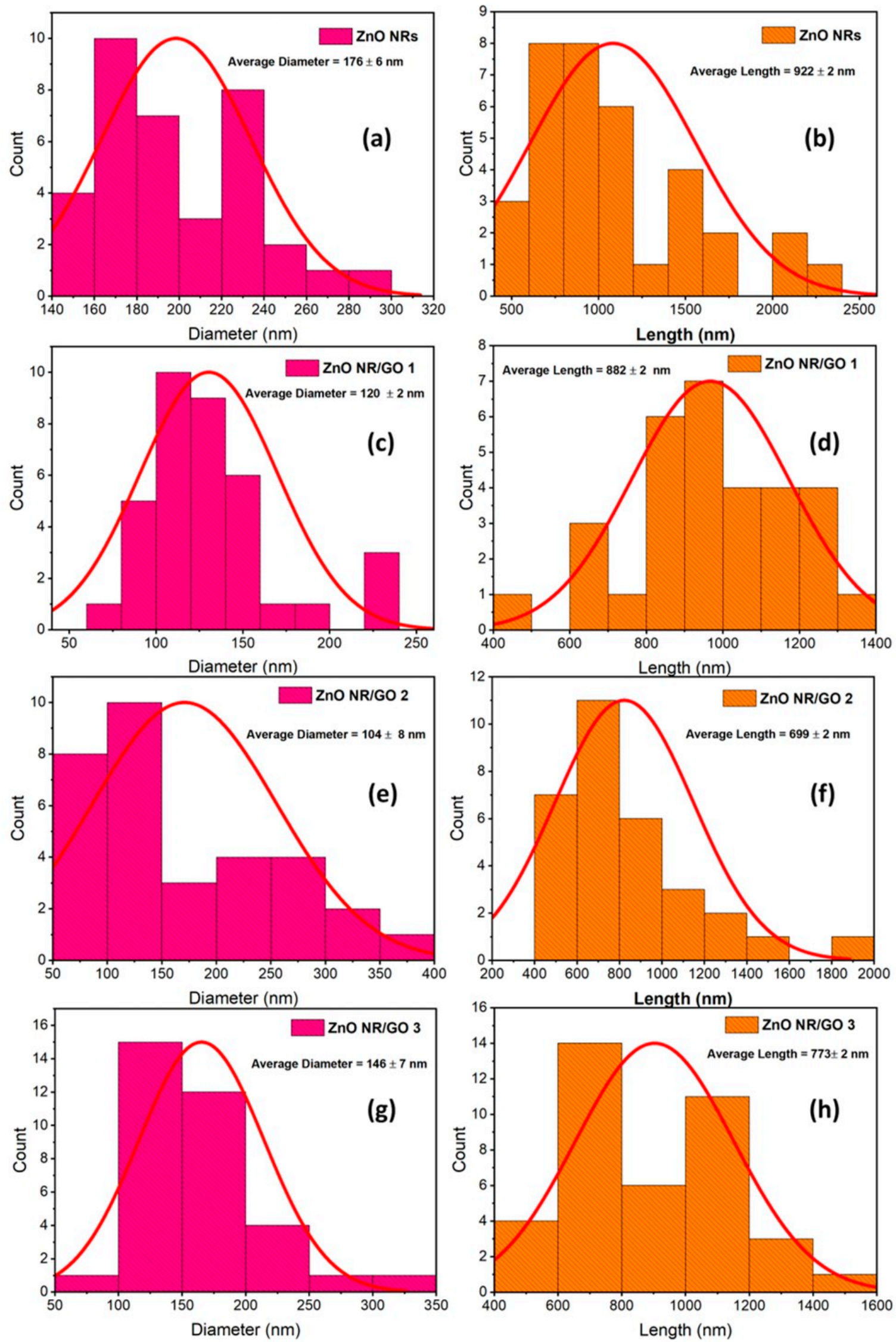

Figure 4. Diameter size distribution $(\mathbf{a}, \mathbf{c}, \mathbf{e}, \mathbf{g})$ and length size distribution $(\mathbf{b}, \mathbf{d}, \mathbf{f}, \mathbf{h})$ of $\mathrm{ZnO} \mathrm{NRs}$, ZnO NRs/GO1, ZnO NRs/GO2, and ZnO NRs/GO3 nanocomposites. 


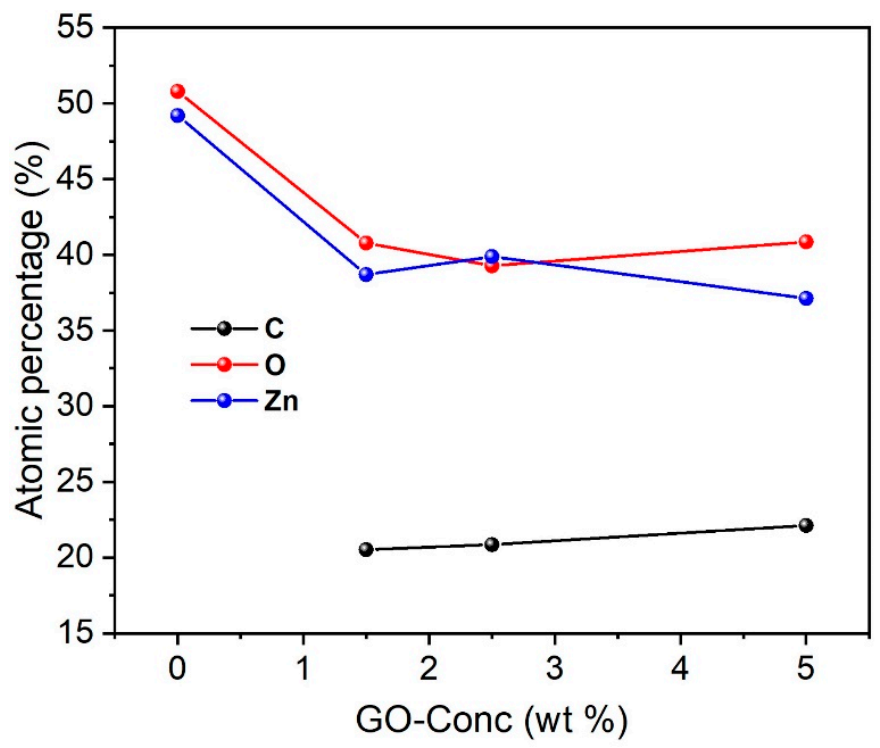

Figure 5. The atomic composition of the $\mathrm{ZnO} \mathrm{NRs} / \mathrm{GO}$ nanocomposites with the different GO concentrations.

\subsection{FTIR and Raman Analysis}

FTIR spectroscopy was used to investigate the surface functional groups in GO layers, ZnO NRs, and $\mathrm{ZnO} \mathrm{NRs} / \mathrm{GO}$ nanocomposites. Figure 6 indicates the presence of eight absorption bands in the FTIR spectrum of GO. The absorption peaks located at $3541-3367 \mathrm{~cm}^{-1}$ can be ascribed to O-H group stretching vibration, while the peaks between 2907 and $2232 \mathrm{~cm}^{-1}$ correspond to the asymmetric and symmetric stretching vibrations of $\mathrm{C}-\mathrm{H}[28,29]$. The bands observed at $1726 \mathrm{~cm}^{-1}, 1615 \mathrm{~cm}^{-1}$, and $1416 \mathrm{~cm}^{-1}$ are attributed to $\mathrm{C}=\mathrm{O}, \mathrm{C}=\mathrm{C}$, and $\mathrm{C}-\mathrm{O}-\mathrm{C}$ stretching vibrations, respectively [30]. Additionally, the band located at $1222 \mathrm{~cm}^{-1}$ can be ascribed to $\mathrm{C}-\mathrm{OH}$ stretching vibrations [31]. The FTIR spectrum of ZnO NRs comprises several absorption bands (blue curve). The absorption peak at $828-540 \mathrm{~cm}^{-1}$ agrees with $\mathrm{Zn}-\mathrm{O}$ stretching vibration. The absorption peak at $1227 \mathrm{~cm}^{-1} \mathrm{can}^{\mathrm{be}}$ attributed to $\mathrm{C}-\mathrm{OH}$ stretching vibrations [31]. The peaks around $2905 \mathrm{~cm}^{-1}$ are attributable to C-H bonds. The absorption band located at $3421 \mathrm{~cm}^{-1}$ corresponds to the hydroxyl group [32]. The FTIR spectra of the ZnO NRs/GO nanocomposites exhibit a number of absorption bands lying in the range from 400 to $4000 \mathrm{~cm}^{-1}$. The peaks at 549 and $849 \mathrm{~cm}^{-1}$ can be ascribed to $\mathrm{Zn}-\mathrm{O}$ stretching vibration, thus confirming the presence of $\mathrm{ZnO}$ in nanocomposites [33]. Furthermore, the peak observed around $1266 \mathrm{~cm}^{-1}$ can be assigned to C-OH stretching vibration [31], that shifted from $1222 \mathrm{~cm}^{-1}$ in the case of GO due to composite formation. The absorption peaks at 2949 and $2289 \mathrm{~cm}^{-1}$ are attributable to the $\mathrm{C}-\mathrm{H}$ and $\mathrm{O}=\mathrm{C}=\mathrm{O}$ stretching vibrations, respectively [26], while the absorption band around $3411-3610 \mathrm{~cm}^{-1}$ is owing to the $\mathrm{O}-\mathrm{H}$ stretching vibration. It is recognized that any change in the position and intensity of FTIR peaks of ZnO NRs/GO nanocomposites with respect to those of GO reflects the contribution of functional groups of $\mathrm{GO} / \mathrm{ZnO}$ nanorods [17].

Raman spectroscopy is a powerful characterization technique, particularly useful for further analysis of the structural properties of $\mathrm{ZnO}$ and related composites. The GO spectrum (Figure 7a), exhibits two sharp peaks at $1344 \mathrm{~cm}^{-1}$ and $1599 \mathrm{~cm}^{-1}$, labeled as D and G bands, respectively [34]. The D band is related to a structural disorder of graphene, whereas the $\mathrm{G}$ band is assigned to the $\mathrm{sp}^{2}$ hybridized carbon atoms $(C=C$ stretching), hence confirming the presence of carbon in nanocomposites [34].

Figure $7 \mathrm{~b}$ shows the Raman spectrum of $\mathrm{ZnO}$ nanorods. The peaks around $325 \mathrm{~cm}^{-1}$ and $436 \mathrm{~cm}^{-1}$ correspond to the polar and $E_{2}$ (high) vibrational modes of the $\mathrm{ZnO}$ structure, respectively, confirming the hexagonal wurtzite phase of $\mathrm{ZnO}$ nanorods [35]. The peak at $\sim 569 \mathrm{~cm}^{-1}$ is due to the $\mathrm{A}_{1}$ (LO) mode of $\mathrm{ZnO}$ [36], whereas the peak found at $1100 \mathrm{~cm}^{-1}$ corresponds to the phonon scattering phenomenon [37]. 
For the $\mathrm{ZnO} / \mathrm{GO}$ nanocomposites (Figure 7c), all three Raman spectra exhibited identical spectral characteristics, with six leading Raman-active regions, i.e., four regions for the $\mathrm{ZnO} \mathrm{NRs}$ and the other two regions associated with the GO (D and G bands), which confirms the successful formation of nanocomposites. The only difference was the peaks' intensity that increased with increasing GO concentration (Figure 7d). Moreover, in the case of the nanocomposite, the D and G bands are shifted to lower wavenumbers, $1334 \mathrm{~cm}^{-1}$ and $1594 \mathrm{~cm}^{-1}$, compared to $\mathrm{GO}$, due to the hybridization of $\mathrm{ZnO}$.

Furthermore, the peak positions of the $\mathrm{D}$ and $\mathrm{G}$ bands of $\mathrm{GO}$ and $\mathrm{ZnO}$ NRs/GO nanocomposites were nearly identical, whereas the intensity ratio of the $\mathrm{D}$ and $\mathrm{G}$ bands $\left(\mathrm{I}_{\mathrm{D}} / \mathrm{I}_{\mathrm{G}}\right)$ changed (Figure $\left.7 \mathrm{e}\right)$ : $I_{\mathrm{D}} / I_{\mathrm{G}}=0.92,1.00,1.03$, and 1.05 for GO, ZnO NRs/GO1, ZnO NRs/GO2, and ZnO NRs/GO3, respectively. It is well known that the intensity peak ratio of the $\mathrm{D}$ and $\mathrm{G}$ bands indicates the degree of structural defect concentration in graphitic materials [38]. The increase in the $\mathrm{I}_{\mathrm{D}} / \mathrm{I}_{\mathrm{G}}$ ratio for ZnO NRs/GO nanocomposites attests that the defect concentration in $\mathrm{ZnO} \mathrm{NRs} / \mathrm{GO}$ is higher than in GO, due to the effect of the hydrothermal treatment on the formation of both $\mathrm{ZnO}$ and $\mathrm{GO}$.

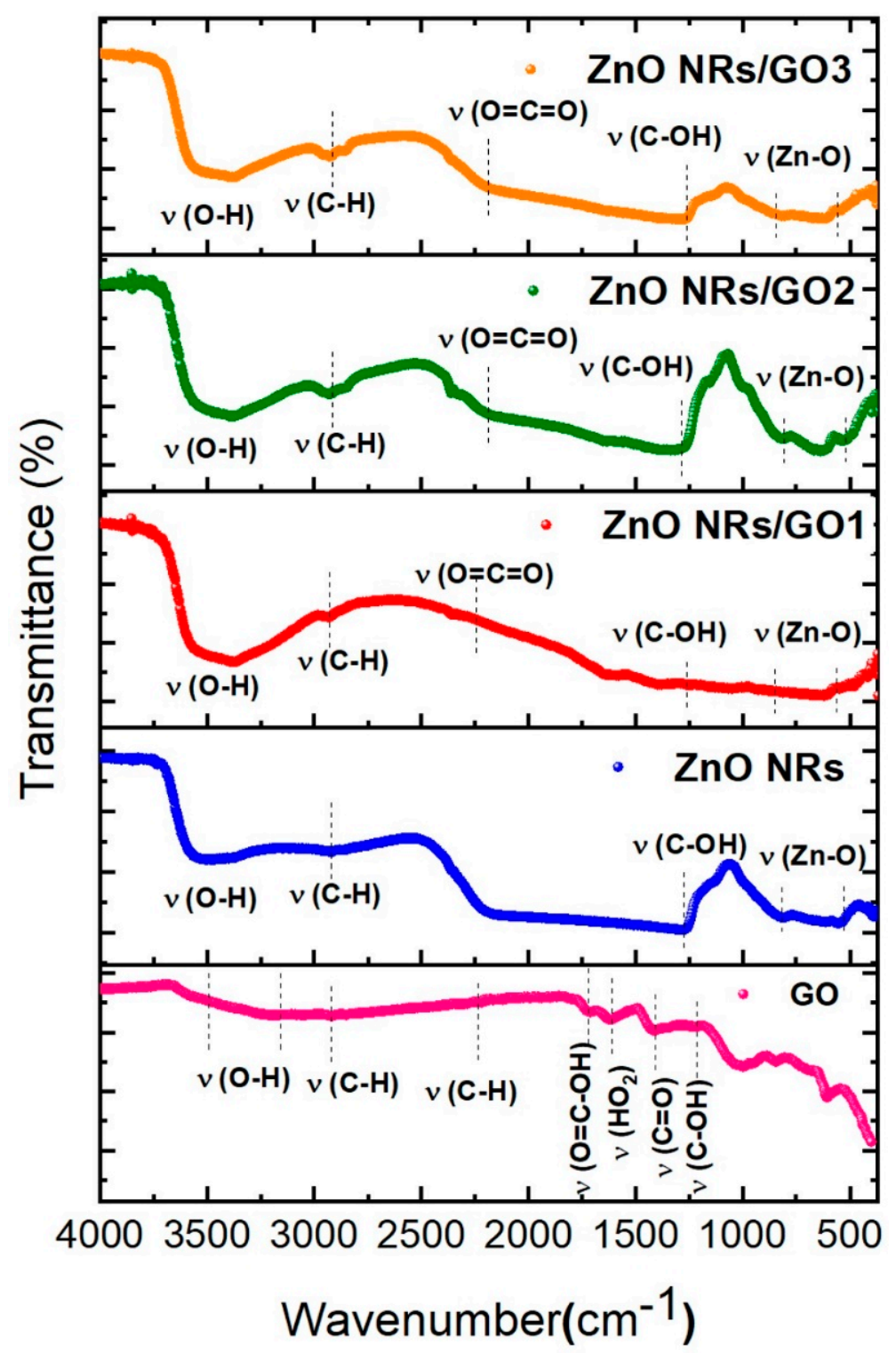

Figure 6. Fourier transform infrared (FTIR) spectra of GO, ZnO NRs, and ZnO NRs/GO nanocomposites with different GO concentrations. 

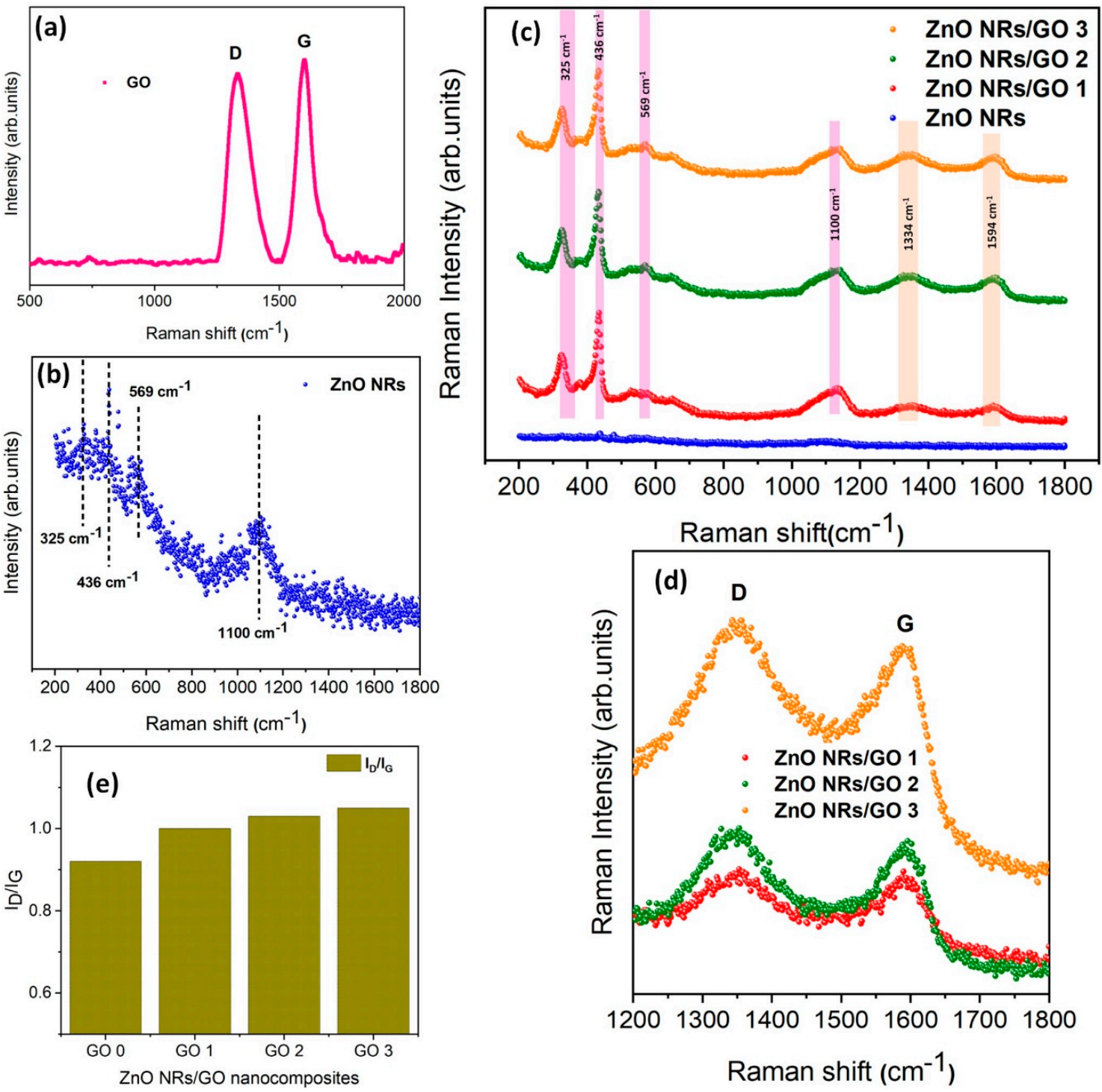

Figure 7. Raman spectra of (a) GO, (b) ZnO NRs, (c) ZnO NRs/GO nanocomposites with different GO concentrations, (d) Raman spectra of the same samples shown in the higher region $\left(1200-1800 \mathrm{~cm}^{-1}\right)$, and $(\mathbf{e})$ the variation of $\left(I_{\mathrm{D}} / I_{\mathrm{G}}\right)$ intensity ratio with $\mathrm{GO}$ concentrations.

\subsection{UV-Vis Absorption Spectroscopy}

The UV-Vis absorption spectra of the $\mathrm{ZnO}$ NRs and $\mathrm{ZnO}$ NRs/GO nanocomposites with various concentrations of GO are shown in Figure 8. The strong absorption peaks at $366-370 \mathrm{~nm}$, characteristic for all spectra, can be related to the electron transitions from the valence band to the conduction band $\left(\mathrm{O}_{2 \mathrm{p}}-\mathrm{Zn}_{3 \mathrm{~d}}\right)$ [38]. No apparent absorption was observed in the visible region. In general, the absorption spectrum of GO exhibits two main particularities, namely the absorption peak at around $230 \mathrm{~nm}$, which is attributed to the $\pi-\pi^{*}$ transition, and the absorption peak at around $300 \mathrm{~nm}$, due to the $\mathrm{n}-\pi^{*}$ transition of aromatic $\mathrm{C}-\mathrm{C}$ bonds [39]. As can be shown, the absorbance of the $\mathrm{ZnO}$ NRs/GO1 increases compared to that of the $\mathrm{ZnO}$ NRs due to the absorption contribution of GO. Moreover, when compared to $\mathrm{ZnO} / \mathrm{GO}$ nanocomposites, the absorption edges are gradually redshifted for $\mathrm{ZnO} \mathrm{NR} / \mathrm{GO} 2$ and $\mathrm{ZnO}$ $\mathrm{NRs/GO3} \mathrm{nanocomposites,} \mathrm{due} \mathrm{to} \mathrm{the} \mathrm{interaction} \mathrm{of} \mathrm{ZnO}$ NRs with GO.

The optical band gap of the composites was evaluated by a Tauc plot, based on the following relation [40]:

$$
(\alpha h v)^{2}=\mathrm{A}\left(h v-\mathrm{E}_{\mathrm{g}}\right)
$$


where $h v$ is the photon energy, $\alpha$ is the absorption coefficient, A is an energy independent constant, and $\mathrm{E}_{\mathrm{g}}$ is the band gap. Figure 9 shows the variation of $(\alpha h v)^{2}$ versus $\mathrm{h} v$ in the fundamental absorption region. The inferred band gap values of the $\mathrm{ZnO}$ NRs nanocomposites are around $3.10 \mathrm{eV}$.

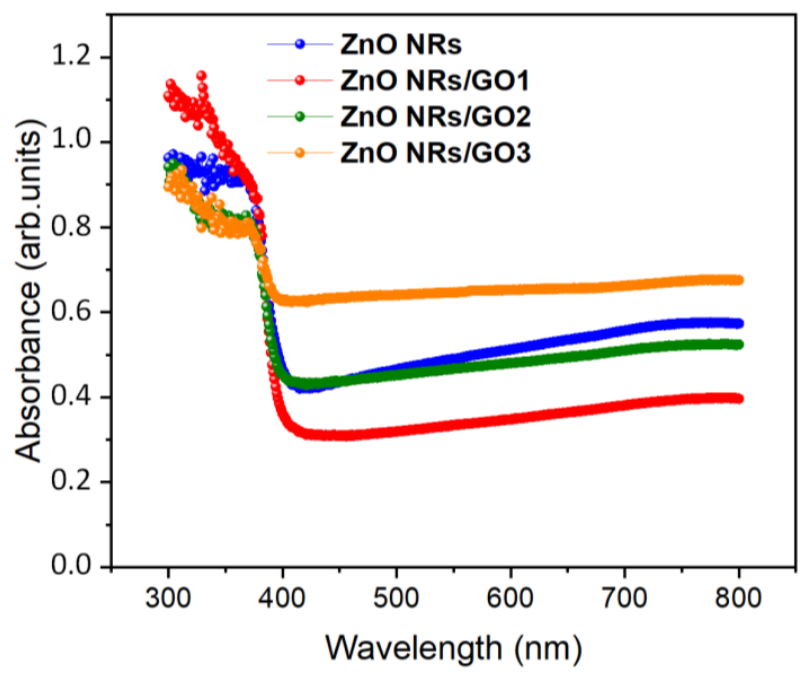

Figure 8. Absorbance spectra of $\mathrm{ZnO}$ NRs and $\mathrm{ZnO}$ NRs/GO nanocomposites.

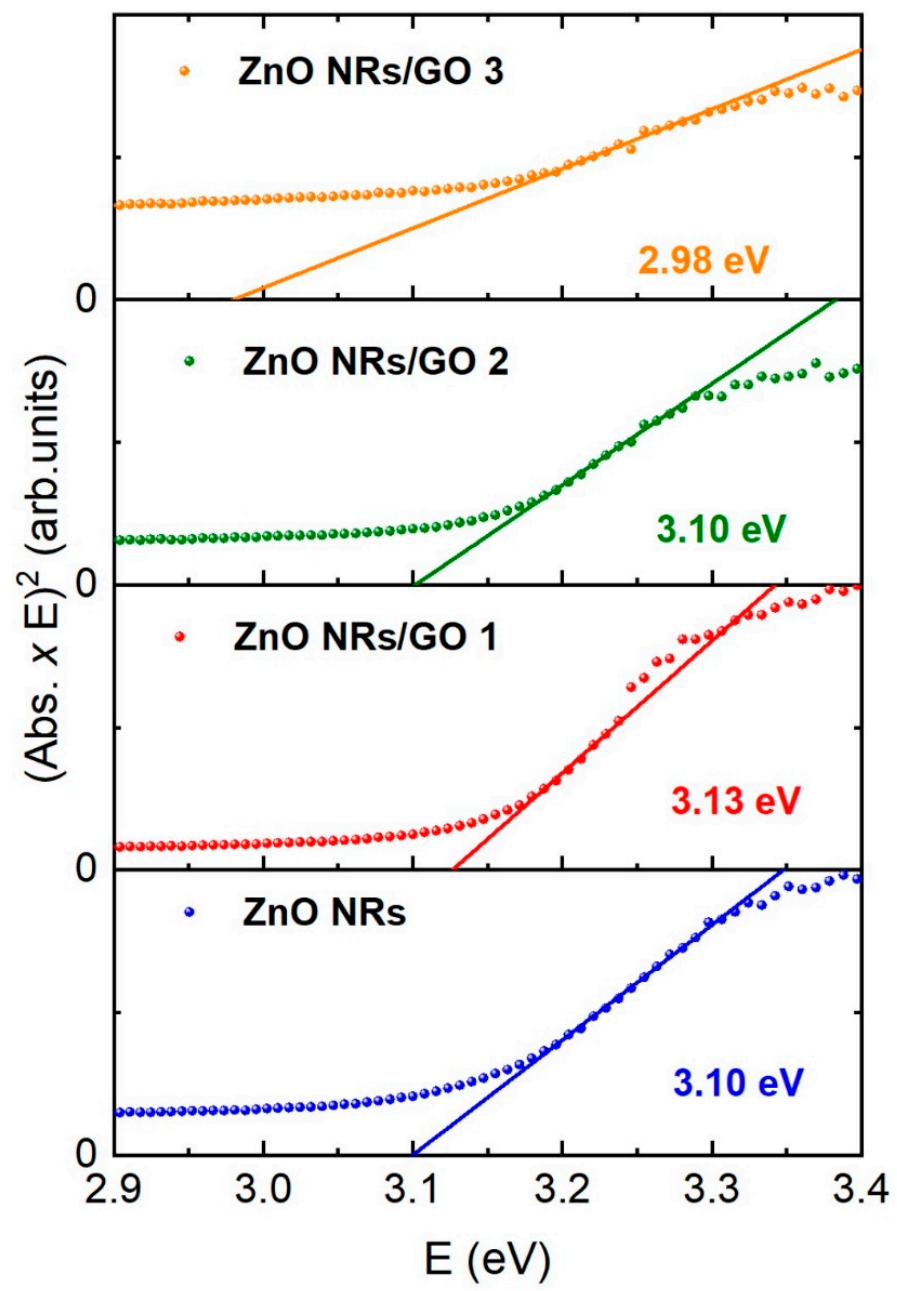

Figure 9. Tauc plots to determine the energy band gaps on the GO amount in $\mathrm{ZnO}$ NRs and $\mathrm{ZnO}$ NRs/GO nanocomposites. 


\subsection{Photoluminescence Spectroscopy}

The PL spectra of ZnO NRs and ZnO NRs/GO nanocomposites, recorded with a $325 \mathrm{~nm}$ excitation wavelength, are shown in Figure 10. As can be easily ascertained, the samples display three spectrally distinct PL bands - the low intensity band with maximum at $387 \mathrm{~nm}$ (UV emission), the low intensity band centered at $425 \mathrm{~nm}$ (blue emission), as well as the high intensity and sharp band peaked at $575 \mathrm{~nm}$ (green emission). The near-band-edge (NBE) UV emission is due to free ZnO exciton recombination [16]. The blue emission at $425 \mathrm{~nm}$ is attributed to the electron transition from a shallow donor level of zinc interstitials $\left(\mathrm{Zn}_{\mathrm{i}}\right)$ to the top of the valence band (VB) [41]. The green emission peak observed around $565 \mathrm{~nm}$ is due to the transitions from the oxygen vacancy (VO) level of ZnO NRs [42]. Moreover, as shown by PL spectra, the luminescence is substantially quenched after the addition of GO, due to the interaction between excited $\mathrm{ZnO}$ NRs and GO. As GO concentration is increased, the PL intensity is decreased, which is caused by the interfacial charge transfer between ZnO NRs and GO layers [43,44].

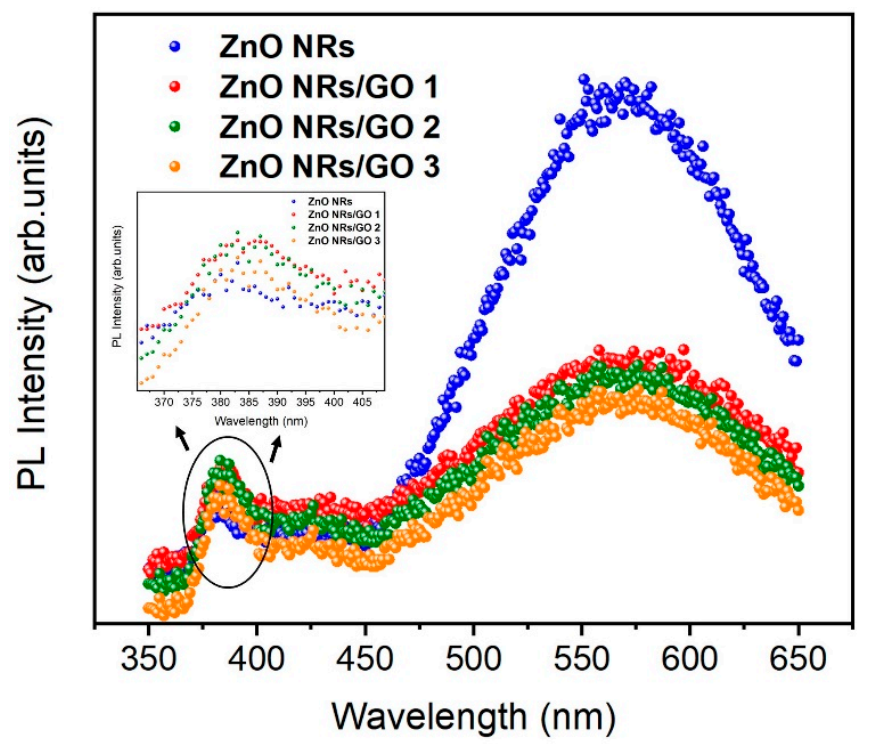

Figure 10. Photoluminescence (PL) spectra of $\mathrm{ZnO}$ NRs and $\mathrm{ZnO}$ NRs/GO nanocomposites (inset shows room temperature PL spectra in the ultraviolet (UV) region of ZnO NRs and ZnO NRs/GO nanocomposites).

For a more detailed analysis of emission bands, Figure 11a-d shows the Gaussian fitting of the PL spectra of ZnO NRs and ZnO NRs/GO nanocomposites. In each case, three PL peaks were fitted for the broad visible emission band (in the range of 450-650 nm) and one peak for the UV emission peaked at around 382-388 nm. Apparently, samples exhibit luminescence bands at 517-521 nm that can be related to the emission from defect states due to the presence of oxygen functional groups [45]. Two others peaks at 565-570 $\mathrm{nm}$ and 618-624 $\mathrm{nm}$ were associated with optical transitions from the VO level and extended oxygen vacancy states to the valance band, respectively [42,46]. It can be also ascertained that when GO's concentrations increased, emission bands of ZnO NRs/GO exhibited a redshift as compared to those of $\mathrm{ZnO}$ NRs. This may be attributed to the interaction between the surface defects of $\mathrm{ZnO}$ and the $\pi$-electron cloud of the graphene [47]. Studies regarding the theoretical evaluation of optoelectronic properties of 2D materials were published previously. It was demonstrated that localization of electronic states plays a key role in determining the properties of the considered systems [48].

The PL intensity of the UV region is increased; however, in the visible region it is decreased by increasing the GO concentration (inset of Figure 10). The $I_{\mathrm{vis}} / I_{\mathrm{UV}}$ ratio represents one of the important factors for comparing optical characteristics. When comparing the optical properties of nanocomposites, 
the $\mathrm{I}_{\mathrm{UV}} / \mathrm{I}_{\mathrm{vis}}$ ratio of $\mathrm{ZnO}$ NRs/GO2 means fewer structural defects and a better crystalline quality than the other nanocomposites (ZnO NRs/GO1, ZnO NRs/GO3) (Figure 12a).
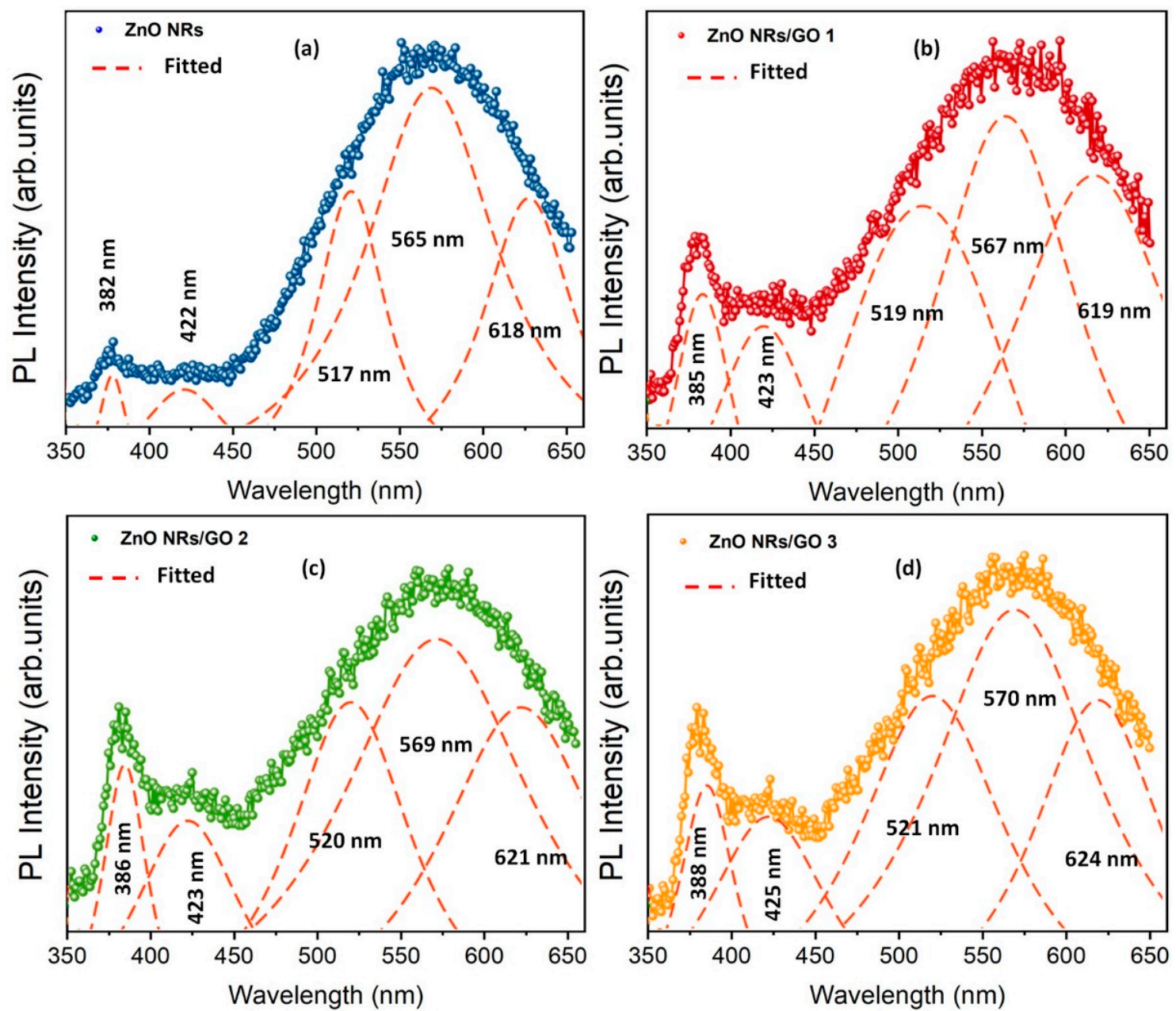

Figure 11. Gaussian line-shape fitting of the PL spectra of (a) ZnO NRs, (b) ZnO NR/GO1, (c) ZnO $\mathrm{NR} / \mathrm{GO}$, and (d) ZnO NR/GO3 nanocomposites (solid and dashed lines represent the experimental and the fitted data, respectively).
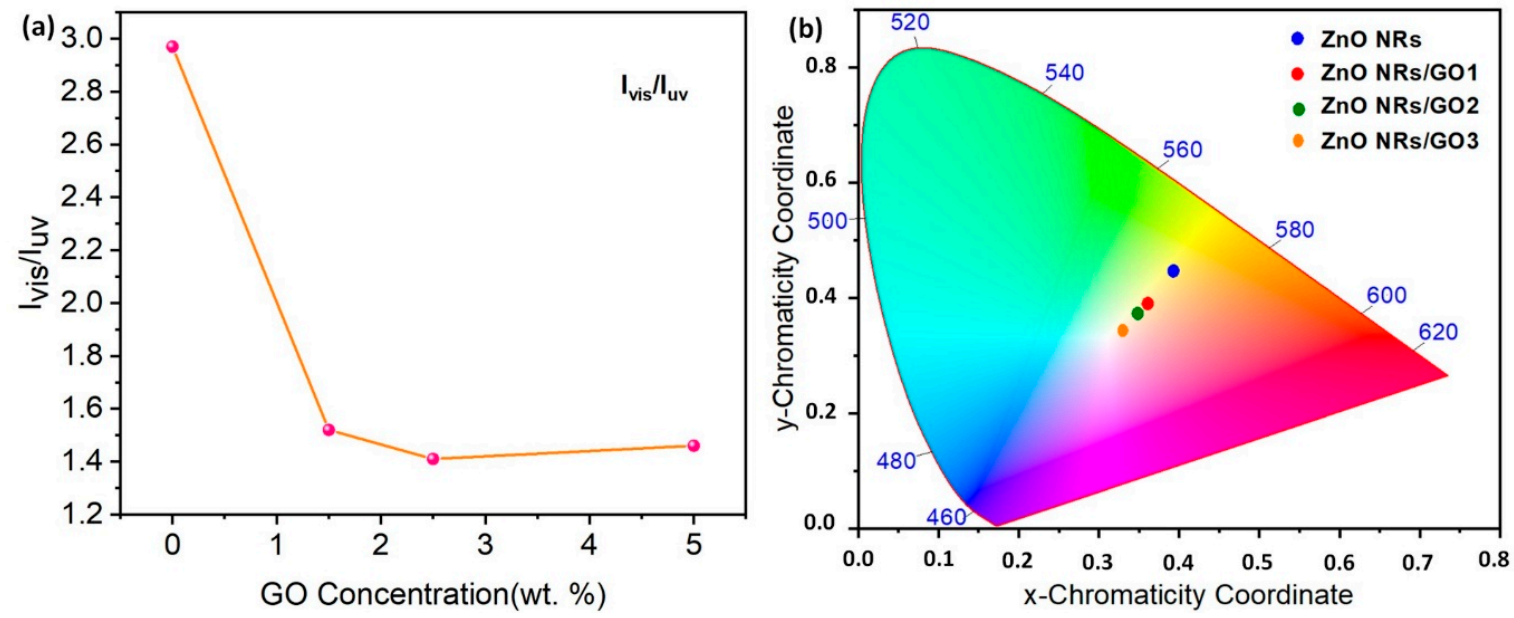

Figure 12. (a) The variation of $I_{\mathrm{vis}} / I_{\mathrm{UV}}$ peak intensity ratio with GO concentration; (b) CIE chromaticity diagram for $\mathrm{ZnO}$ NRs and $\mathrm{ZnO}$ NRs/GO nanocomposites. 
However, the emissions have been also characterized by calculating chromaticity color coordinates, using the CIE 1931 chromaticity diagram (Figure 12b). The color coordinates of ZnO NRs were estimated to be about $(0.39,0.44)$, corresponding to green-orange emission. Clearly, the emission from $\mathrm{ZnO}$ nanorods does not belong to the white light region. The obtained color coordinates for $\mathrm{ZnO} N R s / G O 1$, $\mathrm{ZnO} \mathrm{NRs/GO2,} \mathrm{and} \mathrm{ZnO} \mathrm{NRs/GO3} \mathrm{were} \mathrm{found} \mathrm{to} \mathrm{be}(0.36,0.39),(0.35,0.37)$, and $(0.33,0.34)$, respectively, and display a shift towards the white light coordinates $(0.33,0.33)$ with the increase in GO concentration. We believe that our findings are likely to pave the way for realizing white light emission by means of $\mathrm{ZnO} / \mathrm{GO}$ nanocomposites. The obtained results could be even used for commercial LED application.

\section{Conclusions}

The nanocomposites were successfully prepared via the hydrothermal process. The XRD measurements indicated the formation of the hexagonal wurtzite structure of ZnO. The SEM and EDX studies revealed the formation of GO layers and flower-shaped $\mathrm{ZnO}$ NRs. A decreasing grain size tendency together with increasing amount of GO was observed. The UV-Vis spectra revealed that the nanocomposites exhibited redshifted absorption peaks compared to pure ZnO NRs, with the strongest absorption around $370 \mathrm{~nm}$. The PL spectra of the nanocomposites showed a strong near-band-edge UV emission at 350-400 $\mathrm{nm}$ and large visible emission bands at 500-650 $\mathrm{nm}$. The obtained results also indicated the impact of GO concentration on the optical properties of the $\mathrm{ZnO}$ NRs. Moreover, the color coordinates of $\mathrm{ZnO} \mathrm{NRs} / \mathrm{GO}$ nanocomposites are close to the white light coordinate $(0.33,0.33)$.

Author Contributions: I.B. and M.G. conceived and designed the experiments, M.K., M.E., A.C. and M.G. performed the experiments, I.B., M.K., L.L., A.C.G., M.E., A.J. and I.Z. analyzed the data, A.C.G., M.E., A.C. and B.M.M. contributed reagents/materials/analysis tool I.B., M.A., L.L., M.G., A.C.G. and M.E. wrote, review and edited the paper. All authors have read and agreed to the published version of the manuscript.

Funding: A.C.G. and M.E. acknowledge the financial support from the Romanian Ministry of Education and Research in the framework of Core Program PN19-03 (contract no. 21 N/08.02.2019). This research was funded by UEFISCDI, project number ERANET-MANUNET-III-MINaFBioS.

Acknowledgments: M.G. acknowledges the Romanian Ministry of Foreign Affairs and the Agence Universitaire de la Francophonie for the Eugen Ionescu research and mobility grant at the National Institute of Materials Physics. This work was supported by a grant from UEFISCDI, project number ERANET-MANUNET-III-MINaFBioS. A.C.G. and M.E. acknowledge the Romanian Ministry of Education and Research in the framework of Core Program PN19-03 (contract no. 21 N/08.02.2019) for the financial support. Special thanks to the Alexandru Ioan Cuza University of Iasi (Romania), the Faculty of Physics, University of South Africa, and the Department of Physics and Africa Graphene Center (South Africa).

Conflicts of Interest: The authors declare no conflict of interest.

\section{References}

1. Yi, G.C.; Wang, C.; Park, W. ZnO nanorods: Synthesis, characterization and applications. Semicond. Sci. Technol. 2005, 20, S22-S34. [CrossRef]

2. Martinez, A.G.; Santana, G.; Güell, F.; Martínez-Alanis, P.R.; Dutt, A. Photoluminescence of ZnO Nanowires: A Review. Nanomaterials 2020, 10, 857. [CrossRef] [PubMed]

3. Wen, B.; Huang, Y.; Boland, J.J. Controllable growth of $\mathrm{ZnO}$ nanostructures by a simple solvothermal process. J. Phys. Chem. C 2008, 112, 106-111. [CrossRef]

4. Fan, Z.; Wang, D.; Chang, P.-C.; Tseng, W.-Y.; Lu, J.G. ZnO nanowire field-effect transistor and oxygen sensing property. Appl. Phys. Lett. 2004, 85, 5923-5925. [CrossRef]

5. Paul, R.; Gayen, R.N.; Biswas, S.; Bhat, S.V.; Bhunia, R. Enhanced UV detection by transparent graphene oxide/ZnO composite thin films. RSC Adv. 2016, 6, 61661-61672. [CrossRef]

6. Xiang, Q.; Yu, J.; Jaroniec, M. Graphene-based semiconductor photocatalysts. Chem. Soc. Rev. 2012, 41, 782-796. [CrossRef]

7. Zhu, C.; Fang, Y.; Wen, D.; Dong, S. One-pot synthesis of functional two-dimensional graphene/SnO 2 composite nanosheets as a building block for self-assembly and an enhancing nanomaterial for biosensing. J. Mater. Chem. 2011, 21, 16911-16917. [CrossRef] 
8. Hsieh, C.-T.; Lin, C.-Y.; Chen, Y.-F.; Lin, J.-S. Synthesis of ZnO@Graphene composites as anode materials for lithium ion batteries. Electrochim. Acta 2013, 111, 359-365. [CrossRef]

9. Wang, H.; Yang, Y.; Liang, Y.; Robinson, J.T.; Li, Y.; Jackson, A.; Cui, Y.; Dai, H. Graphene-wrapped sulfur particles as a rechargeable lithium-sulfur battery cathode material with high capacity and cycling stability. Nano Lett. 2011, 11, 2644-2647. [CrossRef]

10. Kim, J.; Cote, L.J.; Huang, J. Two Dimensional Soft Material: New Faces of Graphene Oxide. Acc. Chem. Res. 2012, 45, 1356-1364. [CrossRef]

11. Brisebois, P.P.; Siaj, M. Harvesting graphene oxide-Years 1859 to 2019: A review of its structure, synthesis, properties and exfoliation. J. Mater. Chem. C 2020, 8, 1517. [CrossRef]

12. Xu, Z.; Gao, C. Graphene chiral liquid crystals and macroscopic assembled fibres. Nat. Commun. 2011, 2, 1-9. [CrossRef] [PubMed]

13. Chen, Y.-L.; Hu, Z.-A.; Chang, Y.-Q.; Wang, H.-W.; Zhang, Z.-Y.; Yang, Y.-Y.; Wu, H.-Y. Zinc oxide/reduced graphene oxide composites and electrochemical capacitance enhanced by homogeneous incorporation of reduced graphene oxide sheets in zinc oxide matrix. J. Phys. Chem. C 2011, 115, 2563-2571. [CrossRef]

14. Vessalli, B.A.; Zito, C.A.; Perfecto, T.M.; Volanti, D.P.; Mazon, T. ZnO nanorods/graphene oxide sheets prepared by chemical bath deposition for volatile organic compounds detection. J. Alloy. Compd. 2017, 696, 996-1003. [CrossRef]

15. Chung, Y.T.; Mahmoudi, E.; Mohammad, A.W.; Benamor, A.; Johnson, D.; Hilal, N. Development of polysulfone-nanohybrid membranes using $\mathrm{ZnO}-\mathrm{GO}$ composite for enhanced antifouling and antibacterial control. Desalination 2017, 402, 123-132. [CrossRef]

16. Rokhsat, E.; Akhavan, O. Improving the photocatalytic activity of graphene oxide/ZnO nanorod films by UV irradiation. Appl. Surf. Sci. 2016, 371, 590-595. [CrossRef]

17. Alamdari, S.; Ghamsari, M.S.; Afarideh, H.; Mohammadi, A.; Geranmayeh, S.; Tafreshi, M.J.; Ehsani, M.H. Preparation and characterization of GO-ZnO nanocomposite for UV detection application. Opt. Mater. 2019, 92, 243-250. [CrossRef]

18. Qi, Y.; Zhang, C.; Liu, S.; Zong, Y.; Men, Y. Room-temperature synthesis of ZnO@GO nanocomposites as anode for lithium-ion batteries. J. Mater. Res. 2018, 33, 1506-1514. [CrossRef]

19. Khorramshahi, V.; Karamdel, J.; Yousefi, R. High acetic acid sensing performance of Mg-doped ZnO/rGO nanocomposites. Ceram. Int. 2019, 45, 7034-7043. [CrossRef]

20. Khenfouch, M.; Buttner, U.; Baïtoul, M.; Maaza, M. Synthesis and characterization of mass produced high quality few layered graphene sheets via a chemical method. Graphene 2014, 3, 7-13. [CrossRef]

21. Bindu, P.; Thomas, S. Estimation of lattice strain in $\mathrm{ZnO}$ nanoparticles: X-ray peak profile analysis. J. Theor. Appl. Phys. 2014, 8, 123-134. [CrossRef]

22. Janotti, A.; van de Walle, C.G. Fundamentals of zinc oxide as a semiconductor. Rep. Prog. Phys. 2009, 72, 126501. [CrossRef]

23. Atchudan, R.; Edison, T.N.J.I.; Perumal, S.; Shanmugam, M.; Lee, Y.R. Direct solvothermal synthesis of zinc oxide nanoparticle decorated graphene oxide nanocomposite for efficient photodegradation of azo-dyes. J. Photochem. Photobiol. A Chem. 2017, 337, 100-111. [CrossRef]

24. Cullity, B.D.; Stock, S.R. Elements of X-ray Diffraction, 3rd ed.; Prentice-Hall: New York, NY, USA, 2001.

25. Saleem, M.; Fang, L.; Ruan, H.B.; Wu, F.; Huang, Q.L.; Xu, C.L.; Kong, C.Y. Effect of zinc acetate concentration on the structural and optical properties of $\mathrm{ZnO}$ thin films deposited by Sol-Gel method. Int. J. Phys. Sci. 2012, 7, 2971-2979. [CrossRef]

26. Li, Y.T.; Xu, J.M.; Tang, Z.J.; Xu, T.T.; Li, X.J. Nearly white light photoluminescence from ZnO/rGO nanocomposite prepared by a one-step hydrothermal method. J. Alloy. Compd. 2017, 715, 122-128. [CrossRef]

27. Fujimoto, $\mathrm{H}$. Theoretical $\mathrm{X}$-ray scattering intensity of carbons with turbostratic stacking and $\mathrm{AB}$ stacking structures. Carbon 2003, 41, 1585-1592. [CrossRef]

28. Zare, M.; Safa, S.; Azimirad, R.; Mokhtari, S. Graphene oxide incorporated ZnO nanostructures as a powerful ultraviolet composite detector. J. Mater. Sci. Mater. Electron. 2017, 28, 6919-6927. [CrossRef]

29. Muda, M.R.; Ramli, M.M.; Isa, S.S.M.; Jamlos, M.F.; Murad, S.A.Z.; Norhanisah, Z.; Isa, M.M.; Kasjoo, S.R.; Ahmad, N.; Nor, N.I.M. Fundamental study of reduction graphene oxide by sodium borohydride for gas sensor application. In Proceedings of the AIP Conference Proceedings, 11th Asian Conference on Chemical Sensors, Penang, Malaysia, 16-18 November 2015; AIP Publishing LLC: Melville, NY, USA, 2017; Volume 1808, pp. 020034-1-020034-6. 
30. Kumar, N.; Srivastava, V.C. Simple Synthesis of Large Graphene Oxide Sheets via Electrochemical Method Coupled with Oxidation Process. ACS Omega 2018, 3, 10233-10242. [CrossRef]

31. Zhang, T.; Zhang, D.; Shen, M. A low-cost method for preliminary separation of reduced graphene oxide nanosheets. Mater. Lett. 2009, 63, 2051-2054. [CrossRef]

32. Chen, X.; He, Y.; Zhang, Q.; Li, L.; Hu, D.; Yin, T. Fabrication of sandwich-structured ZnO/reduced graphite oxide composite and its photocatalytic properties. J. Mater. Sci. 2010, 45, 953-960. [CrossRef]

33. Bano, N.; Hussain, I.; El-Naggar, A.M.; Albassam, A.A. Reduced graphene oxide nanocomposites for optoelectronics applications. Appl. Phys. A 2019, 125, 215. [CrossRef]

34. Kudin, K.N.; Ozbas, B.; Schniepp, H.C.; Prud'Homme, R.K.; Aksay, I.A.; Car, R. Raman spectra of graphite oxide and functionalized graphene sheets. Nano Lett. 2008, 8, 36-41. [CrossRef] [PubMed]

35. Gautam, N.; Singh, F.; Gautam, S.K.; Singh, R.G.; Ojha, S.; Kapoor, A. Growth of highly transparent $\mathrm{Cd}_{\mathrm{x}} \mathrm{Zn}_{1-\mathrm{x}} \mathrm{O}(\mathrm{CZO})$ thin films: Structural and optical studies. J. Alloy. Compd. 2015, 650, 311-317. [CrossRef]

36. Vettumperumal, R.; Kalyanaraman, S.; Santoshkumar, B.; Thangavel, R. Estimation of electron-phonon coupling and Urbach energy in group-I elements doped $\mathrm{ZnO}$ nanoparticles and thin films by sol-gel method. Mater. Res. Bull. 2016, 77, 101-110. [CrossRef]

37. Ye, X.-Y.; Zhou, Y.-M.; Sun, Y.-Q.; Chen, J.; Wang, Z.-Q. Preparation and characterization of Ag/ZnO composites via a simple hydrothermal route. J. Nanoparticle Res. 2009, 11, 1159-1166. [CrossRef]

38. Azarang, M.; Shuhaimi, A.; Yousefi, R.; Sookhakian, M. Effects of graphene oxide concentration on optical properties of $\mathrm{ZnO} / \mathrm{RGO}$ nanocomposites and their application to photocurrent generation. J. Appl. Phys. 2014, 116, 084307. [CrossRef]

39. Lai, Q.; Zhu, S.; Luo, X.; Zou, M.; Huang, S. Ultraviolet-visible spectroscopy of graphene oxides. Aip Adv. 2012, 2, 032146. [CrossRef]

40. Joshi, G.P.; Saxena, N.S.; Mangal, R.; Mishra, A.; Sharma, T.P. Band gap determination of Ni-Zn ferrites. Bull. Mater. 2003, 26, 387-389. [CrossRef]

41. Ahmed, G.; Hanif, M.; Zhao, L.; Hussain, M.; Khan, J.; Liu, Z. Defect engineering of ZnO nanoparticles by graphene oxide leading to enhanced visible light photocatalysis. J. Mol. Catal. A Chem. 2016, 425, 310-321. [CrossRef]

42. Ding, J.; Wang, M.; Zhang, X.; Yang, Z.; Song, X.; Ran, C. Photoluminescence investigation about zinc oxide with graphene oxide \& reduced graphene oxide buffer layers. J. Colloid Interface Sci. 2014, 416, $289-293$.

43. Yang, Y.; Liu, T. Fabrication and characterization of graphene oxide/zinc oxide nanorods hybrid. Appl. Surf. Sci. 2011, 257, 8950-8954. [CrossRef]

44. Son, D.I.; Kwon, B.W.; Yang, J.D.; Park, D.H.; Seo, W.S.; Lee, H.; Yi, Y.; Lee, C.L.; Choi, W.K. Charge separation and ultraviolet photovoltaic conversion of $\mathrm{ZnO}$ quantum dots conjugated with graphene nanoshells. Nano Res. 2012, 5, 747-761. [CrossRef]

45. Hatel, R.; Goumri, M.; Ratier, B.; Baitoul, M. Graphene derivatives/ $\mathrm{Fe}_{3} \mathrm{O}_{4} /$ polymer nanocomposite films: Optical and electrical properties. Mater. Chem. Phys. 2017, 193, 156-163. [CrossRef]

46. Boukhoubza, I.; Khenfouch, M.; Achehboune, M.; Mothudi, B.M.; Zorkani, I.; Jorio, A. Graphene oxide/ZnO nanorods/graphene oxide sandwich structure: The origins and mechanisms of photoluminescence. J. Alloys Compd. 2019, 797, 1320-1326. [CrossRef]

47. Kavitha, M.K.; Gopinath, P.; John, H. Reduced graphene oxide-ZnO self-assembled films: Tailoring the visible light photoconductivity by the intrinsic defect states in ZnO. Phys. Chem. Chem. Phys. 2015, 17, 14647-14655. [CrossRef]

48. Mortazavi, B.; Berdiyorov, G.R.; Shahrokhi, M.; Rabczuk, T. Mechanical, optoelectronic and transport properties of single-layer $\mathrm{Ca}_{2} \mathrm{~N}$ and $\mathrm{Sr}_{2} \mathrm{~N}$ electrides. J. Alloys Compd. 2018, 739, 643-652. [CrossRef]

(C) 2020 by the authors. Licensee MDPI, Basel, Switzerland. This article is an open access article distributed under the terms and conditions of the Creative Commons Attribution (CC BY) license (http://creativecommons.org/licenses/by/4.0/). 